\title{
EXISTÊNCIA E RESISTÊNCIA: O AVANÇO DO AGRONEGÓCIO NOS TERRITÓRIOS TRADICIONAIS AVÁ-GUARANI NO PARANÁ ${ }^{1}$
}

\author{
EXISTENCE AND RESISTANCE: THE ADVANCE OF AGRIBUSINESS OVER \\ THE TRADITIONAL AVÁ-GUARANI TERRITORIES IN THE PARANÁ \\ STATE
}

\author{
Priscila Lini* \\ Carlos Frederico Marés de Souza Filho**
}

\begin{abstract}
Resumo: O agronegócio, em franca expansão no estado do Paraná desde a metade do século XX, prioriza a monocultura intensiva de exportação. O estado, conhecido no contexto econômico como o 'celeiro do Brasil' é o maior produtor de soja e milho do país, além da expressiva participação na avicultura e suinocultura. Desde a década de 1980, as cooperativas agroindustriais vêm ganhando força, congregando a produção de maneira organizada e competitiva. Ocorre que, aquele produtor cooperado, provavelmente o descendente de imigrantes europeus fixados no território pelo trabalho das companhias colonizadoras, adquiriu suas férteis terras em uma complexa cadeia legitimadora. Antes do trabalho das referidas companhias, a terra vermelha do oeste paranaense era ocupada por comunidades tradicionais guaranis, que desde o ciclo da erva-mate já vinham perdendo sua identidade e territorialidade. Com a ação oficializada do estado e a fixação de agricultores 'colonos' nesta região, o indígena perdeu não somente seu espaço físico e região de plantio, mas também o território extenso em que exercia sua cosmologia conforme as tradições ancestrais. Uma vez que o modo tradicional de produção do aváguarani não se enquadra nos critérios de produtividade máxima escalonada, esta população tradicional quando não ignorada, é tratada de maneira absolutamente conflitiva, perdendo paulatinamente seu espaço para a agricultura mecanizada agroexportadora. $\mathrm{O}$ avá-guarani passa a ser encarado como um verdadeiro entrave ao progresso econômico, angariando antipatia da sociedade envolvente, quando na verdade a questão perpassa um sensível e complexo problema socioambiental.
\end{abstract}

Palavras-chave: agronegócio; povos tradicionais; Território.

\begin{abstract}
The agribusiness, which has been expanding in the Paraná state since the midtwentieth century, prioritizes intensive export monoculture. The state, known in the economic context as the 'Brazilian Barn', is the largest soybean and corn producer in the country, in addition to the significant participation in poultry and swine farming. Since the 1980's, agro-industrial cooperatives have been gaining strength, bringing together production in an organized and competitive manner. It turns out that this producer, probably a descendant of European immigrants settled in the territory by the work of the colonizing companies, acquired its fertile lands in a complex legitimating chain. Prior to

\footnotetext{
* Programa de Pós-Graduação em Direito da Pontifícia Universidade Católica do Paraná. E-mail: priscilalini@hotmail.com

** Programa de Pós-Graduação em Direito da Pontifícia Universidade Católica do Paraná. E-mail: carlosmares@terra.com.br.
} 
the work of these companies, the red land of western Paraná was occupied by traditional Guarani communities, which since the cycle of yerba mate had been losing their identity and territoriality. With the official action of the state and the establishment of 'settler' farmers in this region, the indigenous lost not only their physical space and planting region, but also the extensive territory in which they exercised their cosmology according to the ancestral traditions. Since the traditional mode of production of the avá-Guarani does not meet the criteria of maximum staggered productivity, this traditional population, if not ignored, is treated in an absolutely conflictive way, gradually losing its space for mechanized export agriculture. The avá-Guarani is seen as a real obstacle to economic progress, arousing dislike of the surrounding society, when in fact the question runs through a sensitive and complex socio-environmental problem.

Keywords: agribusiness; first nations; Territory;

\section{INTRODUÇÃO}

A porção oeste do estado do Paraná possui uma ocupação relativamente recente. A cidade de Foz do Iguaçu, na fronteira com a Argentina e o Paraguai, uma das mais antigas, teve sua emancipação somente no ano de 1914, e o povoamento efetivo da região data da segunda metade do século XX, a observar que a fundação, desmembramento e emancipação dos municípios da região do oeste e sudoeste paranaense ocorre entre as décadas de 1950 e 1960.

O trabalho de fracionamento e comercialização das terras foi não somente facilitado, mas sim incentivado pelos governos estadual e federal, que por intermédio das chamadas companhias colonizadoras concediam a possibilidade de registro e legitimação da propriedade adquirida pelas ondas de descendentes de imigrantes europeus que se estabeleceram no interior e região serrana dos estados do Rio Grande do Sul e Santa Catarina entre fins do século XIX e início do século XX, e que agora realizavam a marcha na direção noroeste.

A terra, considerada até então vaga, consistiu por muito tempo em um verdadeiro entrave ao desenvolvimento, pois distante do litoral, fora de quaisquer rotas de interesse comercial, interiorana e, por assim dizer atrasada. A partir da fixação daquela boa gente laboriosa e pioneira, a região passaria a experimentar o desenvolvimento típico dos ideais modernizantes estabelecidos no Brasil à época.

O problema é que a terra não era, em verdade, vaga, e sim, ocupada por uma população originária desde tempos ancestrais: os guaranis, os kaigang e, em menor número, os xokleng e xetá. Ocorre que aquela população não se enquadrava naquele ideal progressista em curso, tornando-se um incômodo. Assim, ignorando o indígena, as 
Existência e resistência: o avanço do agronegócio nos territórios tradicionais AváGuarani no Paraná

propriedades rurais foram negociadas e comercializadas, as cidades planejadas foram traçadas e loteadas sem qualquer preocupação com o elemento humano autóctone.

Ademais, aquela terra possuía um potencial em sua integralidade: custo baixo, abundância de árvores nativas para o desbaste, o latossolo vermelho e rico, águas em quantidade e qualidade. Bastava para tanto bons braços e disposição para domá-la e tornála produtiva. Assim, quaisquer inconvenientes a este intento foram rápida e efetivamente eliminados - entre eles o nativo bravio, indolente e inapto ao trabalho, na compreensão dos novos ocupantes do espaço geográfico em ascensão.

Estas gentes ali estabelecidas logo desenvolveram aquela que seria a vocação da região: a agricultura intensiva de soja, milho e a pecuária de corte, especialmente aves e suínos. A fim de aumentar a competitividade e viabilizar o escoamento da produção, os agricultores organizaram-se em cooperativas, atuando ativamente no setor agroindustrial em todas as etapas: produção, armazenamento, logística, escoamento e beneficiamento.

Ademais, na década de 1970 o interesse nacional voltou-se à região quando da construção daquela que por mais de trinta anos seria a maior usina hidrelétrica do mundo - a Usina de ITAIPU Binacional - que com seu reservatório inundou uma área de mais de 1.350 quilômetros quadrados do território fronteiriço entre Brasil e Paraguai, demandando uma complicada reacomodação, em que proprietários, posseiros e comunidades indígenas sofreram graves externalidades.

Assim, a população indígena, aqui mantendo-se o foco especialmente na comunidade avá-guarani, enfrenta desde a ocupação oficializada uma série de agressões, tendo negada sua identidade, territorialidade e seu modo de ser tradicional. O agronegócio é um destes elementos conflitantes, uma vez que a produtividade máxima almejada pelo crescente mercado agroexportador enxerga a presença indígena como um empecilho ao pleno desenvolvimento do potencial produtivo da terra.

\section{O TERRITÓRIO E A TERRITORIALIDADE AVÁ-GUARANI}

A população indígena guarani, tradicionalmente, ocupava um território extenso, desde a mata atlântica meridional, do litoral brasileiro à direção interior do continente, chegando onde atualmente se localiza o Paraguai, norte da Argentina e parte centro-sul da Bolívia.

Especificamente nas proximidades do rio Paraná, concentram-se os grupos avá, mbya e guarani kaiowá, com costumes mais ou menos uniformes, com 
Carlos Frederico Marés de Souza Filho

particularidades em seus dialetos, cestaria, cosmologia e musicalidade. O oeste do Paraná registra maior presença de grupos avá-guarani e mbya-guarani, sendo que estes últimos possuem núcleos populacionais menores (MELIÀ, 2008. p.6)

Considerados 'migrantes permanentes', estabelecem suas comunidades, habitações e roçados por um período de quatro a cinco anos, alternando o espaço quando a terra e fauna local demandam recuperação. Assim, transferem o aldeamento a outro sítio, levando consigo sua estrutura.

Esse traço importante à organização tribal guarani, complementado às andanças e migrações periódicas, possui também um caráter religioso e xamânico. Por isso a compreensão do guarani como seminômade, caçador e guerreiro que se dedica à agricultura de subsistência, utilizando a técnica de roçado e rotação do solo.

Considerando que o avá-guarani realiza seu cotidiano nestas constantes movimentações entre um núcleo populacional a outro, pode-se defini-los como ocupantes de um espaço itinerante (SILVA, 2007. p. 66). A mobilidade, as frequentes visitas entre parentes e amigos de uma aldeia a outra, constituem elemento-chave para a realização do $t e k o^{2}$ na tekoh $a^{3}$ ou seja, à sua compreensão de bem viver no espaço sagrado.

Impor uma limitação ao espaço geográfico, para um avá-guarani, é uma forma de violência. Não é possível, dentro do conceito do teko e da tekoha determinar uma fração territorial fixa a ser permanentemente ocupada - não lhe será possível manter o estado do ñande reko. Em sua condição de 'guataha', (caminhante) são as lembranças de suas passagens, as idas e vindas através deste território (SILVA, 2007, p. 19) a materialização de seu modo de ser e a troca de experiências.

Mais do que as simples relações de propriedade compreendidas ao modo capitalista, o guarani incorpora no espaço uma extensão do ser, englobando os métodos de uso e cultivo à sua complexa cosmologia, que envolve simultaneamente o indivíduo e a comunidade.

O esforço em manter suas tradições e práticas, a resistência vivida nas aldeias e travessias, a defesa de seu território - que muitas vezes lhes custa a vida são os últimos recursos encontrados pelo indígena para perpetuar sua cultura. Se não for para viver a seu modo, se não puder efetivar o teko, sequer vale a pena viver. (LINI, 2015, p. 222)

Este modo de vida tradicional e a ocupação de um território extenso e impreciso, muitas vezes conflitante com as fronteiras dos Estados, condena o avá-guarani 
Existência e resistência: o avanço do agronegócio nos territórios tradicionais AváGuarani no Paraná

a uma situação de fragilidade e incerteza, uma vez que o modelo de demarcação de reservas não se mostra suficiente às suas características culturais e materiais. Este território, coincidente com as propriedades rurais comercializadas desde a metade do século XX, torna-se objeto de intensos conflitos com os agricultores e agentes econômicos na região, relegando o indígena a uma condição de marginalidade e violência.

\section{A OCUPAÇÃO DO TERRITÓRIO DO OESTE PARANAENSE: A PROMESSA DA TERRA ROSSA}

A ocupação efetiva da porção oeste e sudoeste do estado do Paraná é um tanto nova, a contar da primeira vila militar fundada na atual cidade de Foz do Iguaçu no início do século XX, com finalidade de demarcação territorial nas frágeis bordas do rio Paraná.

Ocorre que, o processo de ocupação e delimitação na fronteira oeste não teve homogeneidade ou continuidade, ocorrendo em ciclos distintos. As primeiras notícias da região das grandes cataratas remontam ao adelantado Alvar Nuñez Cabeza de Vaca, ainda no século XVI. No início do século XVII, os padres jesuítas estabeleceram as missões religiosas com os guaranis na região chamada de Guairá, porém, as investidas dos bandeirantes paulistas forçaram migrações em massa, redirecionando as missões catequéticas na direção sul (atual estado do Rio Grande do Sul, no Brasil, província de Missiones, na Argentina e departamento de Itapuã, no Paraguai).

Após um vácuo de quase duzentos anos, em fins do século XIX, as obrajes de exploração de erva-mate e madeira proliferam-se da localidade de Guaíra até Foz do Iguaçu, empregando o indígena como mão de obra sob intensa exploração e trabalho exaustivo. Estas organizações, de natureza extrativista exportadora, abriram os primeiros portos fluviais na região, e reavivaram a atenção àquele espaço antes ermo e inexplorado, ali permanecendo até meados da década de 1930.

\footnotetext{
Na década de 1930, com o movimento denominado de 'marcha para o oeste', o governo brasileiro incentivou a migração para a ocupação de terras fronteiriças e do interior do país. Construiu-se a concepção de 'vazio demográfico', quase despovoado, que deveria ser ocupado pela colonização pioneira. Essa ideia teve grandes repercussões entre pesquisadores que analisaram a história da região. Historiadores, geógrafos, sociólogos, representantes políticos, integrantes de órgãos de colonização eternizaram a visão do 'vazio demográfico' em livros e materiais de divulgação. Essa versão repetiu-se nos livros didáticos, importantes mecanismos de normatização de ideias na época, utilizando, principalmente, termos como 'sertão', 'terras devolutas', 'mata virgem' ou ‘boca do sertão’ (MOTA, 2005).
} 
Os municípios circunvizinhos têm entre si muitas similitudes, principalmente na forma de ocupação e emancipação. Isso se deve à tarefa modernizante tomada pelo estado, e levada a cabo com o auxílio das companhias colonizadoras, legitimava aquela propriedade que por tanto tempo permaneceu na condição de res nullius, coisa de ninguém - muito embora este não seja um fato verdadeiro, a considerar pela população tradicional e pelos posseiros que ocupavam o espaço em pequenas unidades de produção familiar, especialmente da cultura da hortelã.

As companhias colonizadoras Maripá - Industrial Madeira e Colonizadora Rio Paraná Ltda., Industrial Agrícola Bento Gonçalves, Pinho e Terras Ltda., Colonizadora Gaúcha Ltda., Colonizadora Matelândia, Colonizadora Criciúma, Sociedade Colonizadora União D'Oeste Ltda. e Colonizadora Norte do Paraná, dentre outras menores, foram fundamentais neste processo.

Tal situação se justifica pois deveriam se dedicar às atividades relacionadas à madeira, à indústria, ao comércio e à venda das terras (PRIORI et al, 2012, p.82), atraindo um expressivo contingente de migrantes da região sul do Brasil com promessas de rápido retorno em terras de alta produtividade, povoando estrategicamente o espaço vago, servindo duplamente ao interesse estatal, tanto na tarefa de delimitação das imprecisas fronteiras ocidentais, quanto na geração de riquezas com a agropecuária intensiva.

\footnotetext{
Numa perspectiva social, o Paraná possui um amplo histórico de conflitos que envolve a disputa por terras. Nas regiões Sudoeste e Oeste do Paraná não foi diferente. Isso porque geralmente as terras doadas ou vendidas às colonizadoras estavam em sua maioria ocupadas por posseiros e essas empresas se encarregaram de expulsá-los (PRIORI et al, 2012, p. 83-84).
}

Os novos ocupantes - orgulhosamente denominados 'pioneiros' na região eram selecionados rigorosamente. Chama a atenção que a venda desses lotes era feita de preferência para gaúchos e catarinenses, em sua maioria com ascendência alemã ou italiana (PRIORI et al, 2012, p. 83). Assim, aparentemente resolvidos os problemas com a titulação e comercialização das terras, cidades planejadas e bem traçadas foram ganhando forma, circundadas por propriedades rurais dedicadas ao plantio da soja, milho e feijão, assim como as primeiras criações de suínos e aves.

A formação e a consolidação da pequena propriedade rural nos três Estados do
Sul do Brasil devem-se sobretudo à imigração estrangeira. O caráter específico
da integração dos Estados do extremo sul desde o período colonial até a
Revolução de 1930 fez com que a imigração para esses Estados fosse
decorrente de outros fatores e tivesse resultados diferentes de outros Estados,
como São Paulo. Enquanto a imigração estrangeira para São Paulo visava
basicamente o suprimento de mão-de-obra para a lavoura cafeeira, que passaria 
Existência e resistência: o avanço do agronegócio nos territórios tradicionais AváGuarani no Paraná

a substituir a mão-de-obra escrava, para os Estados do extremo sul a finalidade básica da imigração era a ocupação efetiva do solo e sua defesa da fronteira com os países do Prata (LANDO e BARROS, 1976, p. 40-41).

Empreendida com sucesso a venda dos lotes, as companhias aos poucos foram se retirando, deixando um legado de progresso, no entendimento capitalista mercantil. Com a curiosa Lei Estadual no 4.245 de 25 de julho de 1960, que criou no "Quadro Territorial do Estado" mais de cinquenta municípios por desmembramento, no período de governo de Moysés Lupion, o oeste do estado ganha cidades pujantes, ansiosas por progresso. Medianeira, Palotina, Marechal Cândido Rondon e Matelândia são exemplos de municípios criados na mesma data, pela mesma lei, e que passam a demandar uma acomodação política interessante.

Nesta acomodação política, não se pode ignorar a importância da organização das lideranças locais, como forma de aumentar o poder de negociação e pressão por melhorias de infraestrutura para armazenamento e escoamento da produção. A lei de cooperativas, do ano de 1971, traria uma resposta bastante atrativa para este modelo em implantação. Assim, a partir da consolidação dos jovens municípios produtores de gêneros agrícolas em franca valorização, a região, antes esquecida, passa a protagonizar uma atenção totalmente nova: a de produtora e fornecedora de gêneros agrícolas de exportação.

\section{O AGRONEGÓCIO COMO VOCAÇÃO}

A terra vermelha do oeste paranaense, rica em minerais, somada à abundância de água e mata nativa, formou um cenário de altíssima produtividade. Atualmente, somente na safra 2015/2016 foram colhidas 18,08 milhões de toneladas de soja (DERAL/PR, 2016) e produzidas 4 milhões de toneladas de frango no ano de 2015 (DERAL/PR, 2016). Assim, logicamente, o valor de mercado das propriedades vem aumentando progressivamente.

A vocação da região, cantada nos hinos dos jovens municípios, é a agricultura - moderna, mecanizada e eficiente. A população, em sua maioria, sente-se orgulhosa dos números e sucessivos recordes de produção atingidos ano a ano, agradecendo a ação das cooperativas, que fazem atividades e atrações diversas nestas localidades, como shows musicais e feiras de exposições - estabelecendo uma relação que, embora proselitista, é vista com bons olhos por todos aqueles que, direta ou indiretamente obtêm sua renda da 
atividade agropecuária.

É fato que o salto produtivo, em grande parte, se deve à ação cooperativista. Isso porque quando os produtores nos idos da década de 1960 passaram a se organizar coletivamente, a fim de aumentar o poder de negociação com a política local e estadual, também conseguiram um poder de mercado significativo.

Cooperativismo no sentido de doutrina que tem por objeto a correção do social pelo econômico através de associações de fim predominantemente econômico, ou seja, as cooperativas; cooperativas no sentido de sociedades de pessoas organizadas em bases democráticas, que visam não só a suprir seus membros de bens e serviços como também a realizar determinados programas educativos e sociais. Trata-se, insistimos, de sociedade de pessoas e não de capital, sem interesse lucrativo e com fins econômico-sociais. Seu funcionamento se inspira nos chamados "Princípios dos Pioneiros de Rochdale": adesão livre, gestão democrática, juros módicos ao capital, retorno proporcional às operações, transações a dinheiro, neutralidade política, religiosa e ética e desenvolvimento do ensino (PINHO, 1966, p.8).

Com as condições de armazenamento e logística facilitadas - a exemplo da abertura da Rodovia Federal BR-277 que cruza o estado do Paraná de um extremo a outro, permitindo o escoamento da produção pelo Porto de Paranaguá - os produtores agrícolas atingiram não somente o mercado nacional, mas também a exportação. Agora, não interessa somente a produção em si, mas sua capacidade de atendimento às demandas de um mercado internacional de commodities.

Desta forma, aquele que antes era um pequeno produtor rural, associado a seus pares com a finalidade de facilitar as etapas produtivas típicas do campo, agora busca formas cada vez mais eficientes de produzir mais e melhor, dentro dos parâmetros exigidos pelo mercado agroexportador.

A pequena produção agrícola formada pela imigração estrangeira foi desde o início o ponto de partida para um processo de expansão permanente dessa forma de produção, através de sucessivos desdobramentos, para mais tarde ser gradativamente incorporada e subordinada ao capitalismo industrial-financeiro (CORADINI e FREDERICQ, 2009. p. 8).

O espírito cooperativista, a partir do momento que encontra um mercado internacional promissor, abandona sua conformação inicial. Se, em princípio é um sistema colaborativo de auxílio e contribuição recíproca entre os cooperados, a partir da incorporação ao mercado externo passa a buscar a máxima produtividade, exigindo dos cooperados uma série de requisitos - nem sempre possíveis de atingir.

As condições sociais que atuam nesse sentido são as próprias condições que, na medida em que integram em termos produtivos a agricultura com a 
Existência e resistência: o avanço do agronegócio nos territórios tradicionais AváGuarani no Paraná

produção industrial e/ou capitalista, em geral a subordinam socioeconomicamente. Essa subordinação da agricultura está assentada no maior desenvolvimento, acumulação e centralização do capital em setores não agrícolas, graças basicamente à maior velocidade da rotação de capital e, portanto, à maior lucratividade nessas esferas da produção (CORADINI e FREDERICQ, 2009. p.15).

A Lei $n^{0} 5.764 / 71$ vem ao encontro das expectativas destas organizações em expansão. Primeiramente, pela série de benefícios oferecidos - tributários, trabalhistas e creditórios; e, em segundo lugar, pela possibilidade da composição e organização em conselhos e pela forma de participação dos cooperados.

Relativamente à legislação vigente, essa organização é considerada como cooperativa, porque cumpre os requisitos legais estabelecidos na legislação. Inclusive, porque a legislação cooperativista prevê a contratação de trabalhadores assalariados, para a realização das atividades-meio e das atividades-fim. A organização do trabalho nessas cooperativas é similar ao das empresas capitalistas tradicionais, em que existem empregadores e empregados. Nesse caso, especificamente, os empregadores se apresentam sob a figura de um grupo de cooperados. Como é o caso, por exemplo, das cooperativas agropecuárias ou de cooperativas de produção de serviços ou das cooperativas médicas em que as atividades-meio são, em regra, realizadas por trabalhadores assalariados (PONTES, 2007. p. 101).

Com o espaço conquistado por estas cooperativas, que passam a atuar em sinergia com os governos locais de maneira decisiva e estratégica, a organização cooperada passa a ser regra, e, as exceções acabam sofrendo certas externalidades. As pequenas propriedades de policultura familiar, apicultores e extrativistas, produtores orgânicos e, de maneira até violenta, os povos tradicionais - todos estes agentes perdem espaço.

Este fato se deve à padronização e a eficiência que serão impostos, pela simples necessidade de produção em escala, típica do mercado agroexportador. A partir deste momento, a fim de atingir os standards desejados, a cooperativa determina ao cooperado o que produzir, como produzir e como comercializar.

Os rigorosos padrões exigidos na produção de suínos e aves, a consultoria de veterinários, zootecnistas, a configuração da propriedade rural - criadouros, "maternidades", “creches", e os investimentos nas granjas são supervisionados de maneira extremamente rigorosa, retirando do produtor a liberdade contratual e produtiva.

Não é diferente com o produtor de grãos, que deve seguir à risca as determinações do agrônomo designado pela cooperativa, que orienta quando plantar, quais cultivares e insumos empregar, e impõe as regras necessárias para atingir o padrão de qualidade exigido nos mercados internacionais. 
Ademais, a organização cooperativa ingressa em todas as etapas produtivas: armazenamento, beneficiamento, industrialização e negociação, movimentando ainda um valioso setor de crédito e administração de títulos agrários.

Tais cooperativas podem ser denominadas também como cooperativas empresariais. Essas cooperativas apresentam as seguintes características: (i) grande parte dos produtores diretos são trabalhadores assalariados; (ii) os cooperados são responsáveis pela gestão, ou a gestão é realizada por técnicos contratados; (iii) a distribuição da renda e das sobras por cooperado é proporcional ao "movimento ou a expressão econômica" realizada por cada cooperado, ao contrário das cooperativas de produção sob o comando dos produtores diretos (PONTES, 2007. p. 102).

Cabe mencionar ainda as relações marginais de dependência impostas, como cobrança de consultorias, de utilização de estruturas de armazenamento e logística, realização de empréstimos, a aquisição de gêneros nos estabelecimentos da própria cooperativa - que vão desde supermercados a postos de combustível - e a retirada de grande parte da autonomia do produtor. A essência colaborativa é perdida neste contexto, permanecendo o termo somente como formalidade, em um sistema capitalista e empresarial clássico, mascarado de relação cooperativista apenas com a finalidade de aproveitar os benefícios da Lei $\mathrm{n}^{\mathrm{o}} 5.764 / 71$.

\section{O AVÁ-GUARANI E SEU ESPAÇO - FORASTEIRO NA PRÓPRIA TERRA}

Embora o território tradicional avá-guarani compreenda um amplo espaço geográfico, desde o período colonial este espaço foi sendo usurpado e remodelado. Além da violência territorial, a exploração da mão de obra indígena no ciclo ervateiro e a eliminação intencional para ceder espaço aos novos habitantes atraídos pelas oportunidades de negócios foram responsáveis por uma verdadeira catástrofe social face a esta população.

Ademais, com a formação do reservatório da Usina de ITAIPU Binacional nas décadas de 1970 e 1980, a realocação dos aldeamentos foi realizada de maneira precária e incorreta, sem levar em conta uma série de particularidades da cultura e do modo de vida avá-guarani.

O povo Avá-Guarani ocupa historicamente a região oeste do Paraná, tendo sofrido inúmeras ações de expropriação por parte do Estado brasileiro ao longo do processo recente de colonização, especialmente durante o governo militar. Nos anos 1970 e 1980, parte desse povo indígena foi compelido a se deslocar para outros locais para viabilizar a ocupação não-indígena na região e permitir 
Existência e resistência: o avanço do agronegócio nos territórios tradicionais AváGuarani no Paraná

o avanço da fronteira agrícola. Além disso, há registros de que a liberação de áreas tradicionais Avá-Guarani no Paraná para a construção da Usina Hidrelétrica de Itaipu contou com ações de remoção forçada deste povo indígena para reservas kaingang e para o Paraguai. À época da construção da Usina, o processo de licenciamento não previa estudos relativos ao componente indígena, que hoje assegura a observância aos seus direitos. (FUNAI, 2013).

A agressão, por parte de particulares, ou mesmo praticada pelo próprio Estado, consiste tanto no desrespeito às práticas ancestrais, à territorialidade, ao uso e concessão das terras, bem como à negação da existência e reconhecimento do aváguarani. Sem levar em conta o critério peculiar de micromobilidade e da ocupação de uma territorialidade específica - o chamado 'espaço itinerante' (SILVA, 2007, p. 66) - reservas exíguas foram concedidas, de forma imprecisa e precária.

Um hábito comum na região é considerar o indígena avá-guarani como um elemento indesejado na dinâmica social, que reclama terras que não são suas. Para tanto, apresentam-se títulos e uma série de prerrogativas de origens controversas, nega-se a nacionalidade e o pertencimento - "são todos paraguaios" dizem em coro os agricultores e autoridades locais - quando não são empreendidas agressões mais sérias: invasões e destruição de aldeamentos, ameaças e até mesmo assassinatos de lideranças indígenas que reclamam um espaço para moradia e cultivo da forma tradicional.

As fronteiras guarani, num passado relativamente recente, passaram a confrontar-se com as fronteiras dos estados nacionais e, também, com frentes econômicas de exploração, alterando e impondo outras fronteiras, mediante a imposição de novas marcas, também rígidas, indicando o que é terra indígena no interior de cada Estado Nacional. A imposição das fronteiras nacionais está relacionada com a necessidade mercantil de unificação alfandegária, cujo resultado presente se revela como produtor de desigualdades (BRAND et al. 2008, p.8).

A estratégia de atribuir ao avá-guarani a condição de estrangeiro na própria terra é bastante conveniente. Institucionalmente, diminuindo o contingente populacional indígena, consequentemente reduz-se a oferta e acesso a políticas públicas de assistência, e dá a falsa minimização de um problema grave e latente. Aos particulares, dá a garantia que as terras permanecerão em sua posse e propriedade de maneira inconteste, para ali empregar os recursos necessários ao bom andamento do agronegócio, com todos os custos socioambientais que acarreta.

O processo colonizador dessa área envolveu tanto as companhias colonizadoras, como os jagunços, posseiros, colonos e grileiros que, em muitos casos, utilizaram-se da violência física ou moral para se apossarem da terra ou defenderem suas propriedades, ou o que consideravam serem os seus domínios 
(PRIORI et al, 2012, p. 85).

Desta forma, enfrentando violentas resistências, institucionalizadas ou não, os avá-guarani buscam o mínimo de respeito ao modo tradicional de vida, ao espaço e acesso à terra - o que é veementemente recusado, uma vez que a concessão de direitos de propriedade e demarcação de terras aos indígenas entra em conflito direto com os interesses da agropecuária intensiva de exportação. Permanece a incerteza, a vulnerabilidade e a insegurança a um povo que apenas reclama o direito legítimo de coexistência em seu modo originário de ser.

\title{
6. QUEM NÃo ESTÁ COM O AGRONEGÓCIO, ESTÁ CONTRA O PROGRESSO
}

A ideia de cooperativa, aplicada no direito civil e empresarial brasileiro, é aquela definida no Art. $3^{\circ}$ da Lei $\mathrm{n}^{\circ}$ 5.764/71: Celebram contrato de sociedade cooperativa as pessoas que reciprocamente se obrigam a contribuir com bens ou serviços para o exercício de uma atividade econômica, de proveito comum, sem objetivo de lucro (BRASIL, 1971).

A ausência de lucratividade é elemento essencial da atividade cooperativa, que, de forma colaborativa, estabelece a economia solidária com a contribuição e partilha de resultados entre todos os cooperados, facilitando as etapas produtivas e concentrando esforços em um objetivo de proveito comum.

\begin{abstract}
Esse tipo de trabalho rompe, por isso, com os paradigmas tradicionais do liberalismo jurídico, uma vez que os movimentos cooperativos surgiram como reação às injustiças sociais, na mesma época em que surge o direito do trabalho. O direito cooperativo, nesta perspectiva, destina-se a estimular a função social da produção, a democratizá-la transferindo, sob a forma de apropriação coletiva dos bens de produção, a capacidade empresarial aos trabalhadores, antes restrita aos detentores do capital (GEDIEL, 2006, p, 5-6).
\end{abstract}

Acontece que este ideal colaborativo vem perdendo espaço, cedendo-o a um critério de máxima lucratividade e verve tipicamente empresarial. Esse desvirtuamento do espírito cooperativo em favor do espírito de lucratividade desvia a entidade, por meios ilegítimos, dos fins sociais - aí incluídas as cooperativas de serviços médicos, cooperativas de crédito e as cooperativas agroexportadoras.

Essa situação, mais a atuação do Estado, contribui para que os setores nãoagrícolas atuem oligopolicamente em relação à agricultura. As próprias 
Existência e resistência: o avanço do agronegócio nos territórios tradicionais AváGuarani no Paraná

condições sociais poderiam contribuir para a formação da empresa capitalista no sentido conceitual do termo, como padrão de desenvolvimento da produção agrícola - evidentemente, na medida em que as condições históricas propiciassem a formação de uma burguesia rural bastante forte para exigir politicamente condições para a realização da taxa média de lucro para o capital investido na produção agrícola (CORADINI e FREDERICQ, 2009, p. 16).

As vantagens do sistema cooperativista são interessantes: tributação diferenciada, relativização dos vínculos de trabalho, redução do custo de produção e a não sujeição à falência, nos termos da Lei $n^{\circ} 5.764 / 71$.

Porém, neste cenário de interesse comercial imediato, que se sobrepõe aos interesses sociais, as pequenas unidades de policultura familiar, produção artesanal e reservas indígenas acabam perdendo espaço, pressionadas por condições limitantes intencionais. Em razão das formas mais restritas de produção - que levam em conta as condições humanas e ambientais com maior preocupação - “[...] de qualquer modo, na medida em que parte dessas pequenas unidades produtivas estariam abaixo das condições razoáveis do ponto de vista produtivo, a tendência seria sua eliminação" (CORADINI e FREDERICQ, 2009, p. 17).

Assim, uma vez que o agronegócio torna-se regra, estimulado por grandes conglomerados agroindustriais exportadores disfarçados em um ato constitutivo de cooperativa, aqueles que não se adaptam à monocultura intensiva ou à pecuária de alta produtividade são considerados rudimentares e atrasados, em contramão ao progresso idealizado pela inserção em um mercado de commodities que condena há tempos o país a uma condição de eterno fornecedor, a um altíssimo custo socioambiental, sem o desenvolvimento de tecnologias sustentáveis.

Entre esses elementos indesejáveis ao progresso estão as populações tradicionais, os avá-guarani que resistem em meio a campos de soja transgênica, granjas de animais confinados, rodovias pedagiadas repletas de caminhões, com inúmeros silos e armazéns às suas margens. Uma população esquecida, condenada a uma invisibilidade social, que conta com a conivência de um Estado interessado somente nas vantagens econômicas de um sistema pernicioso - que se apresenta como a verdadeira vocação do oeste paranaense, e com a antipatia daqueles que impõem as regras do ambiente econômico voltado exclusivamente à obediência ao mercado.

\section{CONCLUSÕES}


A ocupação do oeste do Paraná ocorreu de maneira diferenciada no contexto nacional, tendo em vista a ação oficializada realizada pelo Estado, que, por intermédio das companhias colonizadoras, instalou os descendentes de imigrantes europeus em um espaço aparentemente vago, onde só havia florestas a desbravar e fronteiras a defender.

Em verdade, aquele espaço fracionado e negociado com títulos no mínimo questionáveis, era habitado há tempos imemoriais por uma população tradicional que desde o período colonial de fins do século XVI sofreu toda a sorte de violências no contato com o branco: as comunidades mbyá e avá-guarani.

Desde as reduções jesuíticas, as fugas dos bandeirantes, a exploração do trabalho nos ervais e portos fluviais, a violenta eliminação do território - os avá-guarani resistem às agressões que lhes são direcionadas, e, a partir do século XX essa agressão parte não somente de particulares interessados em suas terras, mas também de um Estado que convenientemente ignora sua condição de fragilidade, e se escusa a prestar o mínimo de atendimento às demandas das comunidades, em detrimento da manutenção do sistema agroindustrial estabelecido pelos colonos que dominaram a região.

A agroindústria se consolidou na região com a atividade das cooperativas, que congregaram os produtores rurais a fim de facilitar o beneficiamento e escoamento da produção. Este sistema recebeu especial incentivo dos governos locais e estadual, com a imposição das cooperativas agroindustriais exportadoras como modelo econômico dominante no oeste paranaense.

Desta forma, aqueles agentes que não correspondem às expectativas da produtividade máxima da monocultura e da pecuária em larga escala são repelidos do sistema econômico local - dentre eles os avá-guarani e seus espaços frágeis e carentes de demarcação. A necessidade de corresponder às demandas econômicas de um mercado internacional ávido por gêneros primários, orienta o pensamento dos particulares e do poder público que direcionam toda sua atenção a este segmento, ignorando aqueles que não se amoldam a este critério.

O agronegócio, assim, adquire um status de modelo ideal, que gera inúmeros empregos e renda a toda uma região. Ocorre que o custo socioambiental é praticamente ignorado, pois, do momento em que este custo for identificado e reconhecido, todo um complexo sistema que envolve poderes políticos e econômicos em âmbito micro e macro será confrontado. Desta forma, aqueles que não se mostram adequados serão oficialmente - ou clandestinamente - erradicados deste sistema.

A imprecisão jurídica das terras tradicionais do oeste paranaense é R. Fac. Dir. UFG, v. 41, n. 3, p.101-116, set/dez. 2017 
Existência e resistência: o avanço do agronegócio nos territórios tradicionais AváGuarani no Paraná

intencional, enquanto aquele produtor rural puder apresentar um sem fim de papéis, títulos e documentos que confirmam sua legítima propriedade, o indígena é considerado um invasor, um mal a ser combatido em nome do bom andamento do agrobusiness.

Desta forma, o que se mantém neste espaço, tradicionalmente ocupado pelo indígena e sucessivamente espoliado, é a fragilidade jurídica, o esfacelamento da identidade, o confim esquecido que necessita se adequar e buscar incessantemente o progresso modernamente compreendido, em que o avá-guarani ou é ignorado ou explorado sucessivamente: desde os encomenderos, passando pelas companhias ervateiras, pelo subemprego e miséria social, mas, principalmente, pelo Estado que permanece em seu ideal colonizador, que impõe o agronegócio e a compreensão da terra como propriedade restrita, limitada e condicionada à produtividade do capital.

\section{REFERÊNCIAS}

BRAND, Antônio et al. Os Guarani nas fronteiras do MERCOSUL. 26 ${ }^{\mathrm{a}}$ Reunião Brasileira de Antropologia, 01 e 04 de junho de 2008, Porto Seguro, Bahia, Brasil.

CORADINI, Odacir Luiz; e FREDERICQ, Antoinette. Agricultura, cooperativas e multinacionais. Rio de Janeiro: Centro Edelstein de Pesquisas Sociais, 2009.

ESTADO DO PARANÁ. Lei $n^{\circ} 4.245$ de 25 de julho de 1960. Cria no Quadro Territorial do Estado, os municípios que especifica.

ESTADO DO PARANÁ. Agência Estadual de Notícias. Paraná bateu recorde de abate de aves e suínos, afirma IBGE. Matéria Publicada em 17/03/2016 17:00. Disponível em: $<$ http://www.aen.pr.gov.br/modules/noticias/article.php?storyid=88323 $>$. Acesso em 17 nov. 2016.

ESTADO DO PARANÁ. Agência Estadual de Notícias. No Paraná, colheita da soja acelera e já alcança 41\% da área plantada. Matéria Publicada em 16/02/2016 12:10. Disponível em: $<$ http://www.aen.pr.gov.br/modules/noticias/article.php?storyid=87885>. Acesso em 17 nov. 2016.

FUNAI - Fundação Nacional do Índio. Esclarecimentos da Funai sobre a presença Avá-Guarani no Oeste do Paraná. Notícia de 10 de junho de 2013. Disponível em: $<$ http://www.funai.gov.br>. Acesso em 11 de novembro de 2016.

GEDIEL, José Antônio Peres. Trabalho, cooperativismo e direito. Ciência e Cultura. v. 58, n. 4. São Paulo: Sociedade Brasileira para o Progresso da Ciência. out./dez. 2006.

LANDO, Aldair; e BARROS, Eliane. A colonização, alemã no Rio Grande do Sul. Porto Alegre, Movimento, 1976.

LINI, Priscila. Ñande reko: o bem-viver guarani como direito humano fundamental. In 
PIOVESAN, Flávia, e FACHIN, Melina Girardi. Direitos humanos na ordem contemporânea: proteção nacional, regional e global. 1ªed. Curitiba: Juruá, 2015.

MELIÀ, Bartomeu. Guarani retã: povos guarani na fronteira Argentina, Brasil e Paraguai. São Paulo: Instituto Socioambiental ISA, 2008.

Koinonia, 2012.

O bem viver guarani: tekó porã. Agenda Latinoamericana. Asunción:

MONTOYA, Antonio Ruiz. Tesoro de la lengua guarani. Madrid, 1639. p. 363. Facsímile da John Carter Brown Library. Disponível em: http://www.brown.edu/academics/libraries/john-carter-brown/. Acesso em 7 de novembro de 2016.

MOTA, Lúcio Tadeu. História do Paraná: ocupação humana e relações interculturais. Maringá: Eduem, 2005.

PINHO, Diva Benevides. A doutrina cooperativa nos regimes capitalista e socialista. 2. ed. São Paulo: Pioneira, 1966.

PONTES, Daniele Regina. Configurações contemporâneas do cooperativismo brasileiro. In GEDIEL, José Antônio Peres (org). Estudos de direito cooperativo e cidadania. n.1. Curitiba: Programa de Pós-Graduação em Direito da UFPR, 2007.

PRIORI, Ângelo, et al. História do Paraná: séculos XIX e XX. Maringá: Eduem, 2012.

SILVA, Evaldo Mendes. Folhas ao vento a micromobilidade de grupos Mbya e Nhandéva (Guarani) na Tríplice Fronteira. Tese de doutorado apresentada ao Programa de Pós-Graduação em Antropologia Social. Rio de Janeiro: Museu Nacional da Universidade Federal do Rio de Janeiro, 2007.

Artigo recebido em 13 de setembro de 2017 e aceito em 25 de novembro de 2017

\footnotetext{
${ }_{1}^{1}$ Pesquisa realizada em período de estágio pós-doutoral. Bolsa PNPD/CAPES 2016/2017.

${ }^{2}$ Teko (teco): ser, estado de vida, condição, estar, lei, costume. (MONTOYA, 1639. p. 363)

${ }^{3}$ Tekoha: lugar de vida e convivência com todos os seres que nela existem. Ñandé tekohá é o lugar onde somos o que somos, o lugar do nosso modo de ser e da nossa cultura. A palavra tekohá contém uma visão holística, isto é, significa e produz ao mesmo tempo relações econômicas, sociais, políticas, ecológicas e religiosas, de tal maneira que sem tekohá não há tekó (sem lugar do ser não há modo de ser). O guarani precisa da terra com toda a sua vida incluída para poder viver sua cultura e para ser guarani. (MELIÁ, 2012. p. 117)
} 